\title{
Burn injuries related to E-cigarettes reported to poison control centers in the United States, 2010-2019
}

\author{
Baoguang Wang ${ }^{*}$ D, Sherry T. Liu, Brian Rostron and Camille Hayslett
}

\begin{abstract}
Background: United States (U.S.) national data indicate that 2035 individuals with burn injuries from e-cigarette explosions presented to U.S. hospital emergency departments (EDs) in 2015-2017. This national estimate is valuable for understanding the burden of burn injuries from e-cigarette explosions among individuals who presented to EDs. However, little is known about individuals who experienced e-cigarette-related burns but may not present to EDs or health care facilities.

Findings: We analyzed data from the National Poison Data System (NPDS) to describe frequency and characteristics of e-cigarette-related burn cases in the U.S. in 2010-2019. NPDS contains information collected during telephone calls to poison control centers (PCCs) across the U.S., including e-cigarette-related burns and other unintended events. During 2010-2019, 19,306 exposure cases involving e-cigarettes were documented in NPDS. Of those, 69 were burn cases. The number of burn cases increased from one in 2011 to a peak of 26 in 2016, then decreased to three in 2019. The majority of the burn cases occurred among young adults aged $18-24$ years $(29.0 \% ; n=20)$ and adults aged 25 years or older $(43.5 \% ; n=30) ; 14.4 \%(n=10)$ occurred among individuals $\leq 17$ years old. Of the 69 burn cases, $5.8 \%(n=4)$ were admitted to a hospital; 65.2\% $(n=45)$ were treated and released; $15.9 \%(n=11)$ were not referred to a health care facility (HCF); $4.4 \%(n=3)$ refused referral or did not arrive at an HCF; and $8.7 \%(n=6)$ were lost to follow-up or left the HCF against medical advice. Nearly one-third $(30.4 \% ; n=21)$ of the cases had a minor effect (symptoms resolved quickly), 47.8\% $(n=33)$ had a moderate effect (symptoms were more pronounced and prolonged than in minor cases, but not life-threatening), and 2.9\% $(n=2)$ had a major effect (life-threatening symptoms).

Conclusions: Approximately one-fifth of e-cigarette-related burn cases reported to PCCs were not referred to or did not arrive at an HCF. Some burn cases had serious medical outcomes. The burn cases mostly affected young adults and adults aged 25 years or older. The number of burn cases in NPDS represents a small portion of ecigarette-related burn cases but it can serve as a complementary data source to traditional injury surveillance systems.
\end{abstract}

Keywords: Electronic cigarette, E-cigarette, Burn, Injury

\footnotetext{
* Correspondence: Baoguang.Wang@fda.hhs.gov

United States Food and Drug Administration, Center for Tobacco Products, Office of Science, 10903 New Hampshire Avenue, Silver Spring, MD 20993, USA
}

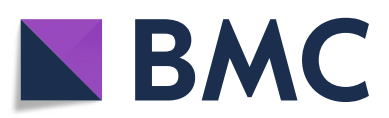

( T) The Author(s). 2020 Open Access This article is licensed under a Creative Commons Attribution 4.0 International License, which permits use, sharing, adaptation, distribution and reproduction in any medium or format, as long as you give appropriate credit to the original author(s) and the source, provide a link to the Creative Commons licence, and indicate if changes were made. The images or other third party material in this article are included in the article's Creative Commons licence, unless indicated otherwise in a credit line to the material. If material is not included in the article's Creative Commons licence and your intended use is not permitted by statutory regulation or exceeds the permitted use, you will need to obtain permission directly from the copyright holder. To view a copy of this licence, visit http://creativecommons.org/licenses/by/4.0/. The Creative Commons Public Domain Dedication waiver (http://creativecommons.org/publicdomain/zero/1.0/) applies to the data made available in this article, unless otherwise stated in a credit line to the data. 


\section{Background}

Despite the increasing popularity of e-cigarette products, particularly among youth and young adults (Cullen et al., 2019; Wang et al., 2018; Creamer et al., 2019; Corey et al., 2018), potential health risks have not been fully characterized. Acute adverse effects associated with e-cigarette use, ranging from burn and explosion injuries to seizures and lung injuries, have been reported (Corey et al., 2018; Rudy \& Durmowicz, 2016; Brownson et al., 2016; Rossheim et al., 2019; Faulcon et al., 2020; Perrine et al., 2019). Rudy and Durmowicz (Rudy \& Durmowicz, 2016) identified 92 e-cigarette-related overheating, fire, or explosion cases between 2009 and 2015 from various data sources, including 13 cases reported to the United States (U.S.) Department of Health and Human Services, Food and Drug Administration (FDA), Center for Tobacco Products (CTP) Safety Reporting Portal (FDA, 2019a) and 21 cases documented in the National Electronic Injury Surveillance System (NEISS). Brownson et al. (Brownson et al., 2016) reported 15 patients with explosion injuries from e-cigarettes treated in one medical center between 2015 and 2016. Of these 15 patients, $80 \%$ had flame burns, 33\% had chemical burns, and $27 \%$ had blast injuries. Two research teams analyzed nationally representative data from NEISS and provided national estimates of e-cigarette-related burn and explosion injuries presenting to U.S. hospital emergency departments (EDs). They estimated that 1007 individuals with battery-related burn injuries presented to EDs in 2016 (Corey et al., 2018) and 2035 individuals with burns and injuries from e-cigarette explosion presented to EDs from 2015 to 2017 (Corey et al., 2018; Rossheim et al., 2019). Although these national estimates are valuable for understanding the burden of e-cigarette-related burn and explosion injuries, the information is limited to individuals who presented to EDs with such injuries. Little is known about individuals who experienced ecigarette-relate burns but may not have presented to EDs or health care facilities.

Unlike NEISS, which collects data from EDs of approximately 100 U.S. hospitals selected as a probability sample of more than 5000 U.S. hospitals with at least five beds and an ED, the National Poison Data System (NPDS) gathers information reported to U.S. poison control centers (PCCs) regarding injuries and poisoning exposures in individuals who may or may not present to EDs or health care facilities. This study describes the frequency and characteristics of e-cigarette-related burn cases documented in NPDS from 2010 to 2019.

\section{Methods}

\section{NPDS data}

In 2019, we analyzed data from NPDS, a data repository of injury and poisoning exposure calls to PCCs in the
U.S. Details on NPDS have been described elsewhere (Wang \& Rostron, 2017). Briefly, NPDS stores information on injury and poisoning events involving more than 437, 000 products, including e-cigarettes and other tobacco products, reported to PCCs (Gummin et al., 2018). Each product is assigned a product code and a generic code. Product codes for e-cigarette devices and liquids became available in 2010 (Gummin et al., 2017; Bronstein et al., 2011; Bronstein et al., 2012). During each telephone call to a PCC, the following information is collected and documented using a structured computer program: information on caller location, exposure site, demographic characteristics of person experiencing poisoning exposure or injury, products involved, clinical effect (i.e., symptoms), level of care at a health care facility (HCF), and medical outcome. The information collected during each telephone call is uploaded to NPDS automatically in approximately $8 \mathrm{~min}$ (Gummin et al., 2018).

PCCs are known for providing information on substance toxicity and advice on poisoning exposure management. However, they respond to telephone calls regarding burns as well. NPDS codes burns as clinical effects, the same way it codes other symptoms, such as vomiting, headache, or abdominal pain. There is a builtin drop-down list of 131 clinical effects in the NPDS database, including superficial burns, second- or thirddegree burns, oral burns, and burns that were not specified. Therefore, data on burns are systematically collected across all PCCs. We identified e-cigarette-related cases by selecting all e-cigarette product codes in NPDS. We then identified e-cigarette-related burn cases by selecting all e-cigarette product codes and clinical effects of burns in NPDS. This study focused specifically on ecigarette-related burns documented as clinical effects in NPDS: superficial burns, second- or third-degree burns, oral burns, and burns that were not specified.

We analyzed NPDS data on burn cases associated with e-cigarettes only (i.e., no other substances were involved) that were reported to PCCs between July 1, 2010 and June 30, 2019. The following cases were excluded from the analysis: confirmed non-exposure $(n=61)$ or burns unrelated to e-cigarettes $(n=717)$; and burns reported from a foreign country $(n=10)$ or overseas diplomatic personnel or US military $(n=4)$.

\section{Case narratives}

In addition to NPDS data, we reviewed case narratives (i.e., free-text notes written by PCC staff for each telephone call to a PCC) to explore context and circumstances of the e-cigarette-related burn cases. The lead author $(\mathrm{BW})$ and a co-author $(\mathrm{CH})$ of this manuscript reviewed all case narratives of burn cases identified for this study and extracted information on pre-defined characteristics. These characteristics included: whether 
e-cigarette explosion occurred (yes or no), type of burns (i.e., thermal burn, chemical burn, or both), affected body part(s), and whether a leaking e-cigarette product (leaking e-liquid) was involved. Information on these characteristics was documented in the free-text case notes of the case narratives with great variation from PCC to PCC, particularly for type of burn. The information on type of burn could be documented in an initial note or follow-up notes and could be noted explicitly or inexplicitly. Inter-reviewer discrepancies on case narrative findings were reconciled by another co-author (STL).

We computed descriptive statistics (i.e., number and percentage of cases) on these topics and calculated Cohen's Kappa statistics to assess inter-reviewer reliability. We conducted data analysis using SAS Version 9.3 (SAS Institute Inc., Cary, NC, USA).

\section{Results NPDS data}

During 2010-2019, 19,306 exposure cases involving ecigarettes were documented in NPDS. Of the 19,306 cases, 69 were e-cigarette-related burn cases. The annual number of e-cigarette-related burn cases increased from one in 2011 to a peak of 26 in 2016, then decreased to three in 2019 (Fig. 1). Table 1 shows NPDS data on the characteristics of these cases. Overall, the majority of burn cases occurred among young adults aged 18-24 years $(29.0 \%)$ and adults aged 25 years or older $(43.5 \%)$. More than one-fifth of the cases occurred among children younger than age 5 years $(2.9 \%)$, adolescents aged $12-17$ years $(11.5 \%)$, and individuals without exact age information (13.0\%) (eight individuals were adults $\geq 20$ years old and one individual had no information on age). There were more male cases $(56.5 \%)$ than female cases. The majority $(69.6 \%)$ of the burn cases were reported by health care professionals. Of the 69 burn cases, 5.8\% $(n=4)$ were admitted to a hospital; $65.2 \%(n=45)$ were treated, evaluated, and released; $15.9 \%(n=11)$ were not referred to an HCF, but include two cases with a moderate effect that were managed on site at a non-HCF; and $4.4 \%(n=3)$ refused referral or did not arrive at an HCF. More than half $(58.0 \% ; n=40)$ of the burn cases had a superficial burn; $36.2 \%(n=25)$ had a second- or thirddegree burn. Nearly one-third $(30.4 \% ; n=21)$ of the burn cases were minor (i.e., symptoms were minimally bothersome to the patient and they usually resolve rapidly), $47.8 \%(n=33)$ were moderate (i.e., symptoms were more pronounced and prolonged than minor cases, but not life-threatening), and $2.9 \%(n=2)$ were major (i.e., symptoms were life-threatening). Approximately twothirds $(61.9 \% ; n=13)$ of burn cases with a minor medical outcome and $81.8 \%(n=27)$ of burn cases with a moderate medical outcome were treated, evaluated, and released (Table 2).

\section{Case narratives}

We reviewed case narratives for all 69 burn cases. The review of the case narratives revealed that approximately two-thirds $(65.2 \% ; n=45)$ of the cases involved ecigarette explosion (Table 1$)$. Nearly two-thirds $(60.9 \%$; $n=42)$ of the cases had thermal burns; $30.4 \%(n=21)$ of the cases had chemical burns; and 7.2\% $(n=5)$ had both thermal and chemical burns. The most frequently reported body part burned was the face $(33.3 \% ; n=23)$, including eyes, nose, lip, and tongue. About one-fourth

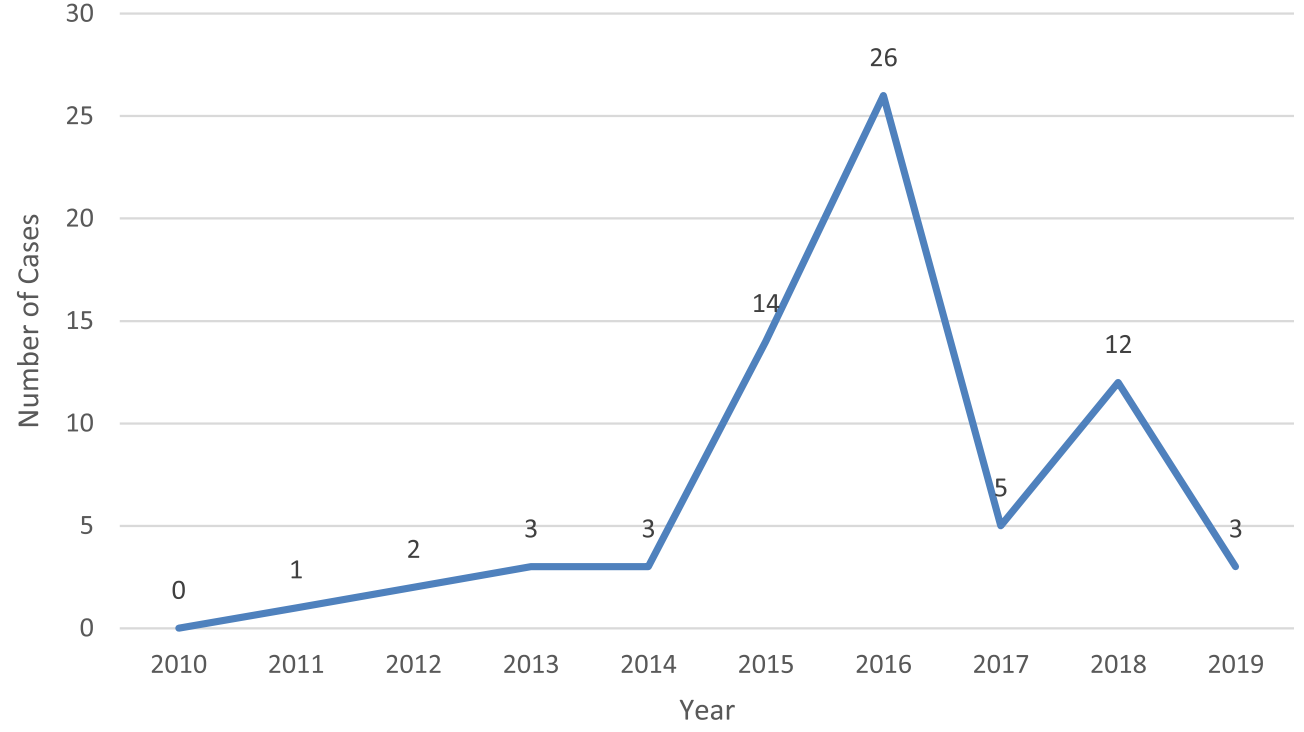

Fig. 1 Number of e-cigarette-related burn cases reported to poison control centers in the United States, 2010-2019 
Table 1 Characteristics of e-cigarette-related burn cases reported to poison control centers in the United States, 2010-2019

\begin{tabular}{ll}
\hline Characteristics & Number (\%) of E-Cigarette- \\
& Related Burn Cases \\
& Overall $(n=69)$ \\
\hline
\end{tabular}

Information from National Poison Data System

\begin{tabular}{|c|c|}
\hline \multicolumn{2}{|l|}{ Age (Years) } \\
\hline$<5$ & $2(2.9 \%)$ \\
\hline $5-11$ & $0(0.0 \%)$ \\
\hline $12-17$ & $8(11.5 \%)$ \\
\hline $18-24$ & $20(29.0 \%)$ \\
\hline $25+$ & $30(43.5 \%)$ \\
\hline $\begin{array}{l}\text { Unknown or Exact Age } \\
\text { Unknown }\end{array}$ & $9(13.0 \%)$ \\
\hline \multicolumn{2}{|l|}{ Gender } \\
\hline Female & $28(40.6 \%)$ \\
\hline Male & $39(56.5 \%)$ \\
\hline Unknown & $2(2.9 \%)$ \\
\hline \multicolumn{2}{|l|}{ Call Site } \\
\hline Heath Care Facility (HCF) & $48(69.6 \%)$ \\
\hline Own Residence & $20(29.0 \%)$ \\
\hline Unknown & $1(1.5 \%)$ \\
\hline \multicolumn{2}{|l|}{ Level of Care at HCF } \\
\hline Admitted to Hospital & $4(5.8 \%)$ \\
\hline Treated, Evaluated, and Released & $45(65.2 \%)$ \\
\hline $\begin{array}{l}\text { Refused Referral or Did Not } \\
\text { Arrive at HCF }\end{array}$ & $3(4.4 \%)$ \\
\hline Lost to Follow-Up or Left AMA & $6(8.7 \%)$ \\
\hline Not Referred & $11(15.9 \%)$ \\
\hline \multicolumn{2}{|l|}{ Clinical Effect } \\
\hline Superficial Burn & $40(58.0 \%)$ \\
\hline 2nd-3rd Degree Burns & $25(36.2 \%)$ \\
\hline Oral Burns & $5(7.3 \%)$ \\
\hline Burns, Not Specified & $7(10.1 \%)$ \\
\hline \multicolumn{2}{|l|}{ Medical Outcome ${ }^{a}$} \\
\hline No Effect & $0(0.0 \%)$ \\
\hline Minor Effect & $21(30.4 \%)$ \\
\hline Moderate Effect & $33(47.8 \%)$ \\
\hline Major Effect & $2(2.9 \%)$ \\
\hline Death & $0(0.0 \%)$ \\
\hline $\begin{array}{l}\text { Not Followed or Unable to } \\
\text { Follow }\end{array}$ & $13(18.8 \%)$ \\
\hline \multicolumn{2}{|l|}{ nformation from Case Narrative Review } \\
\hline \multicolumn{2}{|l|}{ Involved ENDS Explosion } \\
\hline No & $24(34.8 \%)$ \\
\hline Yes & $45(65.2 \%)$ \\
\hline \multicolumn{2}{|l|}{ Involved Leaking } \\
\hline Not Mentioned & $63(91.3 \%)$ \\
\hline
\end{tabular}

Table 1 Characteristics of e-cigarette-related burn cases reported to poison control centers in the United States, 2010-2019

\begin{tabular}{ll} 
(Continued) & $\begin{array}{l}\text { Number (\%) } \\
\text { Related Bur } \\
\text { Overall }(n=69)\end{array}$ \\
\hline Yes & $6(8.7 \%)$ \\
Type of Burn & \\
Thermal & $42(60.9 \%)$ \\
Chemical & $21(30.4 \%)$ \\
Both Thermal and Chemical & $5(7.2 \%)$ \\
Not Specified & $1(1.4 \%)$ \\
Body Part Burned & \\
More than One Body Part & $18(26.1 \%)$ \\
Face Only (including eyes, nose, & $23(33.3 \%)$ \\
lip, and tongue) & \\
Leg/Thigh Only & $13(18.8 \%)$ \\
Hand Only & $10(14.5 \%)$ \\
Shoulder/Chest Only & $1(1.4 \%)$ \\
Genitals Only & $1(1.4 \%)$ \\
Not Specified & $3(4.3 \%)$
\end{tabular}

${ }^{a}$ Medical outcome includes no effect (i.e., the patient did not develop any symptoms), minor effect (i.e., the patient exhibited some symptoms as a result of the exposure, but they were minimally bothersome to the patient and they usually resolve rapidly), moderate effect (i.e., the patient exhibited symptoms, which were more pronounced and prolonged than minor effect, but not lifethreatening), and major effect (i.e., the patient developed symptoms which were life-threatening)

(26.1\%; $n=18$ ) of the cases had burns on more than one body part, followed by burns to only leg/thigh $(18.8 \%$; $n=13)$, hands $(14.5 \% ; n=10)$, shoulder/chest $(1.4 \% ; n=$ $1)$, and genitals $(1.4 \% ; n=1)$. Of all the case narratives we reviewed, six indicated that a leaking product was involved. Agreement between the two reviewers was high for whether e-cigarette explosion occurred (Kappa value $=0.84)$, whether a leaking e-cigarette was involved (Kappa value $=0.84)$, and body part burned (Kappa values $=0.89)$. Kappa value for type of burn was 0.41 .

\section{Discussion}

Data from NPDS, a national surveillance system, indicate that approximately one-fifth of e-cigarette-related burn cases reported to PCCs were not referred to or did not arrive at HCFs. This information is complementary to the findings from previous studies on e-cigarette-related burn injury cases presented to EDs (Corey et al., 2018; Rossheim et al., 2019) and is helpful in understanding the overall burden of e-cigarette-related burn injuries.

Previous studies estimate that more than 1000 ecigarette explosion and burn injuries occur in the U.S. per year (Corey et al., 2018; Rossheim et al., 2019). Only 69 e-cigarette-related burn cases were documented in NPDS from 2010 to 2019. This small number of burn 
Table 2 Level of care at a health care facility by medical outcome for e-cigarette-related burn cases reported to poison control centers in the United States, 2010-2019

\begin{tabular}{|c|c|c|c|c|c|c|}
\hline \multirow{2}{*}{$\begin{array}{l}\text { Level of Care at Health Care } \\
\text { Facility (HCF) }\end{array}$} & \multicolumn{6}{|c|}{ Medical Outcome ${ }^{b}$} \\
\hline & $\begin{array}{l}\text { Total }(n= \\
69)\end{array}$ & $\begin{array}{l}\text { No Effect } \\
(n=0)\end{array}$ & $\begin{array}{l}\text { Minor Effect } \\
(n=21)\end{array}$ & $\begin{array}{l}\text { Moderate Effect } \\
(n=33)\end{array}$ & $\begin{array}{l}\text { Major Effect } \\
(n=2)\end{array}$ & $\begin{array}{l}\text { Not Followed or Unable to } \\
\text { Follow }(n=13)\end{array}$ \\
\hline Admitted to Hospital & $4(5.8 \%)$ & $0(0.0 \%)$ & $0(0.0 \%)$ & $3(9.1 \%)$ & $0(0.0 \%)$ & $1(7.7 \%)$ \\
\hline Treated, Evaluated, and Released & $45(65.2 \%)$ & $0(0.0 \%)$ & $13(61.9 \%)$ & $27(81.8 \%)$ & $1(50.0 \%)$ & $4(30.8 \%)$ \\
\hline $\begin{array}{l}\text { Refused Referral or Did Not } \\
\text { Arrive at HCF }\end{array}$ & $3(4.4 \%)$ & $0(0.0 \%)$ & $1(4.8 \%)$ & $1(3.0 \%)$ & $0(0.0 \%)$ & $1(7.7 \%)$ \\
\hline Lost to Follow-Up or Left AMA & $6(8.7 \%)$ & $0(0.0 \%)$ & $1(4.8 \%)$ & $0(0.0 \%)$ & $1(50.0 \%)$ & $4(30.8 \%)$ \\
\hline Not Referred & $11(15.9 \%)$ & $0(0.0 \%)$ & $6(28.6 \%)$ & $2(6.1 \%)$ & $0(0.0 \%)$ & $3(23.1 \%)$ \\
\hline
\end{tabular}

${ }^{a} A M A$ Against medical advice

${ }^{\mathrm{b}}$ Medical outcome includes no effect (i.e., the patient did not develop any symptoms), minor effect (i.e., the patient exhibited some symptoms as a result of the exposure, but they were minimally bothersome to the patient and they usually resolve rapidly), moderate effect (i.e., the patient exhibited symptoms, which were more pronounced and prolonged than minor effect, but not life-threatening), and major effect (i.e., the patient developed symptoms which were life-threatening)

cases in NPDS may reflect a substantial underreporting commonly suffered by surveillance systems relying on voluntary reporting. Since PCCs' primary goal is to help individuals manage poisoning exposures, many burn cases that required immediate medical attention probably bypassed calling PCCs for help and presented to EDs directly.

We observed the largest number of e-cigarette-related burn cases in 2016 followed by a decline in 2017, a similar observation as noted by Rossheim et al. in their study on e-cigarette-related burn and explosion injuries presenting to EDs (Rossheim et al., 2019). The decline in the number of burn cases from 2016 to 2017 we observed was more pronounced than that reported by Rosseheim et al. This decline coincided with the following events occurring around the time: FDA provided an online education program entitled "Tips to Help Avoid "Vape" Battery Explosions" (FDA, 2017); the U.S. Fire Department published a report of e-cigarette-related fires and explosions in the U.S. and provided information on appropriate use of ecigarettes (McKenna, 2017); and several case series reports of explosion injuries from e-cigarettes in the U.S. were published to alert the public about potential dangers of ecigarette explosions, including two reports by FDA (Rudy \& Durmowicz, 2016; Brownson et al., 2016; Durmowicz et al., 2016). As voluntary reports to PCCs involving ecigarette-related burns can be affected by several factors, such as media coverage and awareness level of free services provided by PCCs, it is unclear whether media and published reports influenced individuals' awareness of ecigarette-related burns, leading to reports to PCCs. Specific reasons for the decline in the number of cases from 2016 to 2017 are difficult to identify with certainty. Given the small number of cases and limitations of NPDS as a passive surveillance system, caution is warranted when interpreting the findings of this study.

One of the unique features of PCCs is their case narratives documenting details on each case, including the circumstances of exposures, the development and progress of the case, treatment and management, and outcome. From the review of case narratives for all 69 burn cases, we noted that six mentioned leaking e-liquids. To our knowledge, this is the first study to suggest that leaky e-cigarettes may be involved in burn injuries. As the landscape of e-cigarettes is evolving rapidly, active surveillance of NPDS, NEISS, social media data, and other data is important for identifying health risks of these products and informing efforts to prevent harm associated with emerging tobacco products (Trigger \& Coleman, 2019; Chang et al., 2019; Wang et al., 2019). FDA has taken steps to address some safety issues associated with e-cigarettes and e-liquids. In November 2019, FDA issued a guidance about its compliance policy for limited safety modifications to certain marketed tobacco products, including battery-operated tobacco products to address battery injury concerns in order to better protect consumers (FDA, 2019b).

One of the major limitations of this study is underreporting, as discussed previously. In addition, selfreported information on burn characteristics is subject to reporting bias, particularly for the burn cases reported by individuals from their own residences, which represent nearly one-third of the burn cases. However, a unique feature of NPDS is the use of follow-up contacts to verify and update information initially reported to PCCs to ensure the accuracy of the information in addition to monitoring case progress, collecting additional information, and determining the medical outcome of the cases (Gummin et al., 2018). Finally, lack of a standard format for case narratives may have resulted in somewhat inconsistent case narrative findings between the two reviewers, particularly for information on type of burn. Unlike the information on explosion and body part burned, type of burn was not directly stated in the case narratives and details sometimes were buried in the progress notes (i.e., follow-up notes) rather than in 
the initial note. The wide variation in case narratives could be the primary reason for the relatively low interreviewer reliability for some of the case narrative findings, such as type of burn. However, the third reviewer reviewed the case narratives to reconcile the discrepancies and provided final coding for the data analysis.

This study analyzed data from a national surveillance system to describe the frequency and characteristics of ecigarette-related burn cases as well as the proportion of those cases that did not present to health care facilities. The number of burn cases documented in NPDS represents a small proportion of total e-cigarette-related burn cases, but it can serve as a complementary data source to other traditional injury surveillance systems, such as NEISS and FDA Safety Reporting Portal (www.safetyreporting.hhs.gov). Findings from case narratives provide additional contextual information that may inform tobacco product labeling, the development of tobacco product standards, and health communication and education programs aimed at preventing e-cigarette-related burns.

\section{Abbreviations}

CTP: Center for Tobacco Products; ED: Emergency Department; FDA: Food and Drug Administration; HCF: Health Care Facility; NEISS: National Electronic Injury Surveillance System; NPDS: National Poison Data System; PCC: Poison Control Center; U.S.: United States

\section{Acknowledgements}

The authors thank Deborah Neveleff for assistance with technical editing. The authors also thank staff at the Headquarters of the American Association of Poison Control Centers and staff at Poison Control Centers across the United States for providing case narratives, which contain valuable information on burn injuries related to e-cigarettes.

\section{Disclaimer}

The findings and conclusions in this report are those of the authors and do not necessarily represent the official position of the Food and Drug Administration.

\section{Authors' contributions}

BW was responsible for data acquisition. BW and STL conceived the study concept. BW, STL, and BR designed the study. STL and BR conducted data analysis and quality control analysis. BW, CH, and STL conducted case narrative review. All authors interpreted findings of data analysis and contributed to the development of this manuscript. All authors read and approved the final manuscript.

\section{Funding}

Funding for this study was supported by the Center for Tobacco Products, U.S. Food and Drug Administration.

\section{Availability of data and materials}

Data for this study are available through contracts with the American Association of Poison Control Centers (www.aapcc.org).

\section{Ethics approval and consent to participate}

This study was determined as exempt by the U.S. Food and Drug Administration (FDA) Institutional Review Board for Human Subject Protection because data were previously collected and did not contain personally identifiable information.
Received: 23 March 2020 Accepted: 4 June 2020

Published online: 20 July 2020

\section{References}

Bronstein AC, Spyker DA, Cantilena LR Jr, Green JL, Rumack BH, Dart RC. 2010 annual report of the American Association of Poison Control Centers' National Poison Data System (NPDS): 28th annual report. Clin Toxicol (Phila). 2011;49(10):910-41.

Bronstein AC, Spyker DA, Cantilena LR Jr, Rumack BH, Dart RC. 2011 annual report of the American Association of Poison Control Centers' National Poison Data System (NPDS): 29th annual report. Clin Toxicol (Phila). 2012;50(10):911-1164.

Brownson EG, Thompson CM, Goldsberry S, Chong HJ, Friedrich JB, Pham TN, et al. Explosion injuries from E-cigarettes. N Engl J Med. 2016;375(14):1400-2.

Chang JT, Wang B, Chang CM, Ambrose BK. National estimates of poisoning events related to liquid nicotine in young children treated in US hospital emergency departments, 2013-2017. Inj Epidemiol. 2019:6(10).

Corey CG, Chang JT, Rostron BL. Electronic nicotine delivery system (ENDS) battery-related burns presenting to US emergency departments, 2016. Inj Epidemiol. 2018;5(1):4.

Creamer MR, Wang TW, Babb S, Cullen KA, Day H, Willis G, et al. Tobacco product use and cessation indicators among adults - United States, 2018. MMWR Morb Mortal Wkly Rep. 2019;68(45):1013-9.

Cullen KA, Gentzke AS, Sawdey MD, Chang JT, Anic GM, Wang TW, et al. eCigarette Use Among Youth in the United States, 2019. JAMA. 2019.

Durmowicz EL, Rudy SF, Chen IL. Electronic cigarettes: analysis of FDA adverse experience reports in non-users. Tob Control. 2016;25(2):242.

Faulcon LM, Rudy S, Limpert J, Wang B, Murphy I. Adverse experience reports of seizures in youth and young adult electronic nicotine delivery systems users. J Adolesc Health. 2020;66(1):15-7.

FDA. 5 Tips to Help Avoid "Vape" Battery Explosions 2017 [Available from: https:// www.fda.gov/media/104399/download.

FDA. FDA Safety Reporting Portal 2019a [cited 2019 August 12]. Available from: https://www.safetyreporting.hhs.gov/SRP2/en/Home.aspx?sid=8d6ef018-a5 76-4e72-87a1-b2d6b24f352c.

FDA. Compliance Policy for Limited Modifications to Certain Marketed Tobacco Products; Guidance for Industry. 2019b.

Gummin DD, Mowry JB, Spyker DA, Brooks DE, Fraser MO, Banner W. 2016 annual report of the American Association of Poison Control Centers' National Poison Data System (NPDS): 34th annual report. Clin Toxicol (Phila). 2017;55(10):1072-252.

Gummin DD, Mowry JB, Spyker DA, Brooks DE, Osterthaler KM, Banner W. 2017 annual report of the American Association of Poison Control Centers' National Poison Data System (NPDS): 35th annual report. Clin Toxicol (Phila). 2018;56(12):1213-415.

McKenna L. In: USF A, editor. Electronic Cigarette Fires and Explosions in the United States 2009-2016. U.S: Fire Administration; 2017.

Perrine CG, Pickens CM, Boehmer TK, King BA, Jones CM, DeSisto CL, et al. Characteristics of a multistate outbreak of lung injury associated with E-cigarette use, or Vaping United States, 2019. MMWR Morb Mortal Wkly Rep. 2019;68(39):860-4.

Rossheim ME, Livingston MD, Soule EK, Zeraye HA, Thombs DL. Electronic cigarette explosion and burn injuries, US emergency departments 2015-2017. Tob Control. 2019;28(4):472-4

Rudy SF, Durmowicz EL. Electronic nicotine delivery systems: overheating, fires and explosions. Tob Control. 2016

Trigger S, Coleman B. Social Media Mentions of Electronic Nicotine Delivery Systems (ENDS) Battery-Related Overheating, Fires, and Explosions: Findings from a Pilot Study. Int J Environ Res Public Health. 2019;16(8).

Wang B, Liu S, Persoskie A. Poisoning exposure cases involving e-cigarettes and e-liquid in the United States, 2010-2018. Clin Toxicol (Phila). 2019:1-7.

Wang B, Rostron B. Tobacco-related poison events involving young children in the US, 2001-2016. Tob Regul Sci. 2017;3(4).

Wang TW, Asman K, Gentzke AS, Cullen KA, Holder-Hayes E, Reyes-Guzman C, et al. Tobacco product use among adults - United States, 2017. MMWR Morb Mortal Wkly Rep. 2018;67(44):1225-32.

\section{Publisher's Note}

Springer Nature remains neutral with regard to jurisdictional claims in published maps and institutional affiliations.

\section{Consent for publication}

Not applicable.

\section{Competing interests}

The authors declare that they have no competing interests. 